\title{
The Influence of the Defect Structure on the Nitriding of Fe by PIII
}

\author{
J. De Baerdemaeker ${ }^{a, *}$, Y. Jirásková ${ }^{b}, \mathrm{P} . \mathrm{SchaAF}^{c}$, \\ D. SEGERS ${ }^{a}$ AND C. DAUWE ${ }^{a}$ \\ ${ }^{a}$ Dpt. Subatomic and Radiation Physics, Ghent University \\ Proeftuinstraat 86, 9000, Gent, Belgium \\ ${ }^{b}$ Institute of Physics of Materials, AS CR \\ Žižkova 22, 616 62, Brno, Czech Republic \\ ${ }^{c}$ Universität Göttingen, II Physikalisches Institut \\ Bunsenstrasse 7-9, 37073 Göttingen, Germany
}

\begin{abstract}
Plasma ion immersion implantation is a promising technique for nitriding. A case study of the characterization of the plasma ion immersion implantation nitriding of iron alloys is the plasma ion immersion implantation nitriding of pure Fe. A set of Fe samples of $99.98 \%$ purity and with different defect structure was plasma ion immersion implantation nitrided at different temperatures. Depth profiling of the samples was achieved using positron annihilation spectroscopy with a slow positron beam and nanoindentation. A correspondence was found between the line shape parameter $S$ and the hardness of the plasma ion immersion implantation treated samples.
\end{abstract}

PACS numbers: 61.72.--y, 61.80.-x, 71.60.+z, 78.70.Bj

\section{Sample preparation}

Discs of $15 \mathrm{~mm}$ diameter and $2 \mathrm{~mm}$ thickness were prepared from an iron rod of $3 \mathrm{~N} 8$ purity. The specimens were ground and polished and annealed in vacuum at $850^{\circ} \mathrm{C}$ for $1 \mathrm{~h}$ followed by a cooling $\left(1^{\circ} \mathrm{C} / \mathrm{min}\right)$ down to room temperature to remove defects that were introduced during specimen machining. The specimens were divided into three groups denoted $A, P$, and $E$. Samples of group $A$ were kept in the annealed state, $P$ and $E$ specimens were surface ground and polished to a $1 \mu \mathrm{m}$ diamond mirror finish, and finally after the polish the surface of the $E$

*corresponding author; e-mail: Jeremie.Debaerdemaeker@UGent.be 
specimens was electrochemically etched. For the electrochemical etching a solution of $90 \mathrm{ml}$ of glacial acetic acid with $10 \mathrm{ml}$ perchloric acid was used as electrolyte at $40 \mathrm{~V}$ for $1 \mathrm{~min}$, resulting in a thickness of the removed surface layer of approximately $1 \mu \mathrm{m}$. Plasma ion immersion implantation (PIII) was performed by the MARK-1 device [1] using a hot wall system at 300,400 , and $500^{\circ} \mathrm{C}$ for $3 \mathrm{~h}$. The pulses were set at $100 \mathrm{~Hz}$ and $100 \mathrm{~ms}$ at $30 \mathrm{kV}$. The plasma was generated at a nitrogen pressure of $1 \times 10^{-2}$ mbar and $300 \mathrm{~W}$ rf-power resulting in an average dose of $1.8 \times 10^{18} \mathrm{at} / \mathrm{cm}^{2}$ for all specimens.

\section{DBAR measurements}

The Doppler broadening of the annihilation radiation (DBAR) measurement were performed using the Ghent Slow positron facility which is fully described in [2]. Depth profiling was achieved by varying the implantation energy of the slow positrons from 0.1 to $30 \mathrm{keV}$ corresponding to mean implantation depths up to $1 \mu \mathrm{m}$. The results are presented in Fig. 1 using the $S$ line shape parameter.

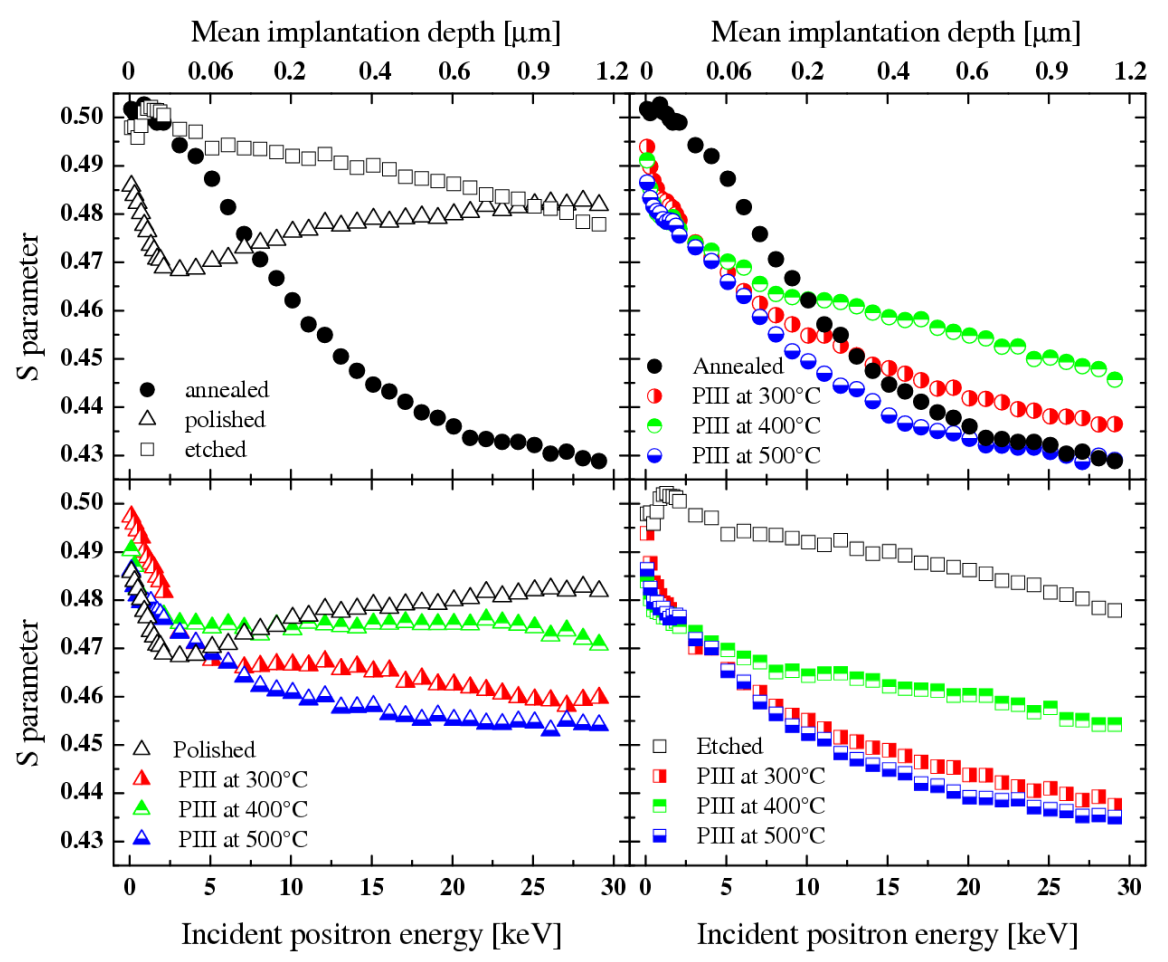

Fig. 1. DBAR $S$ parameter depth profile of iron samples prior and after PIII nitriding at different temperatures.

The virgin annealed sample shows a surface $S$ parameter of 0.502 which evolves down to a value of 0.430 corresponding to the defect free state. This is 
confirmed by positron annihilation lifetime measurements. The positron lifetime of the virgin annealed sample is $105 \mathrm{ps}$, this value is in good agreement with the literature value of $106 \mathrm{ps}$ for defect free Fe [3]. The polished sample shows a surface layer (probably oxide) indicated by a decreasing $S$ parameter from the surface up to an incident energy of $2.5 \mathrm{keV}$ corresponding to a mean implantation depth of $20 \mathrm{~nm}$. Deeper in the sample the $S$ parameter increases from a value of 0.468 to values higher than 0.480 . This indicates the presence of open volume defects deeper than $1 \mu \mathrm{m}$ due to the polishing and a change of either the defect type or the defect concentration in function of depth. The etched sample also shows a surface layer of several $\mathrm{nm}$. The high $S$ value of 0.480 at $1 \mu \mathrm{m}$ for the etched sample also indicates that the etching did not fully remove the defectuous zone introduced by the polish.

For all the PIII treated samples a top layer is visible indicated by a decreasing $S$ from the surface up to a mean implantation depth of $20 \mathrm{~nm}$. This value corresponds to the top of the vacancy profile calculated by transport of ions in matter (TRIM) [4] for nitrogen ions implanted in iron with an incident energy of $30 \mathrm{keV}$ [5]. The treatment temperatures do not seem to remove this defect structure. The signature of the subsurface layer introduced by the polishing vanishes for treatment temperatures higher than $300^{\circ} \mathrm{C}$. The $S$ parameter at $1 \mu \mathrm{m}$ for all the samples is presented in Fig. 2a. For each implantation temperature the polished sample has the highest $S$ value followed by the etched sample. For the different treatment temperatures the $S$ parameters are the highest for the PIII at $400^{\circ} \mathrm{C}$ and the lowest for the PIII at $500^{\circ} \mathrm{C}$.

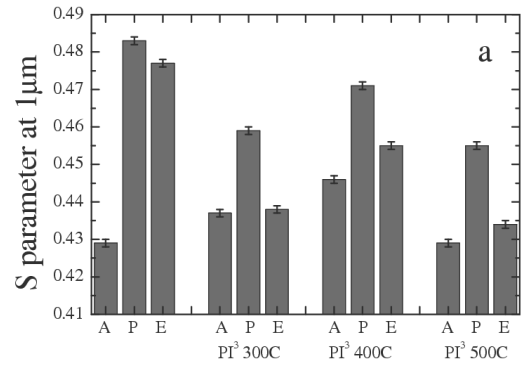

Treatment

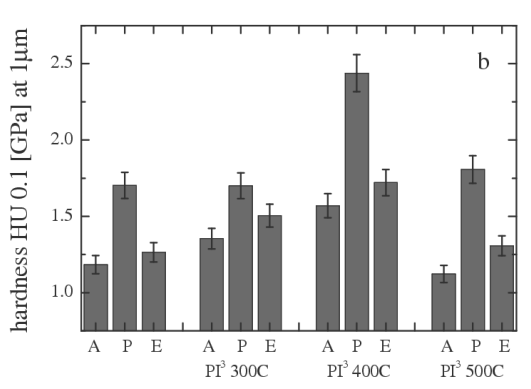

Treatment

Fig. 2. (a) $S$ parameter at $1 \mu \mathrm{m}$; (b) hardness at $1 \mu \mathrm{m}$.

\section{Nanoindentation analysis}

Depth profile nanoindentation measurements were performed using a FISCHER HV 100 XYProg. The results of the nanoindentation measurements are summarized by presenting the hardness at $1 \mu \mathrm{m}$ in Fig. 2b. The samples PIII treated at $300^{\circ} \mathrm{C}$ are significantly harder than the virgin samples for the annealed and the etched sample. The implantations at $400^{\circ} \mathrm{C}$ result in the overall hardest 
layers. It must also be noticed that only these samples show a pronounced subsurface $(100 \mathrm{~nm} \longleftrightarrow 250 \mathrm{~nm})$ region with a hardness of $3 \mathrm{GPa}$ for the annealed and etched samples and a value of $6 \mathrm{GPa}$ for the polished sample. The polished sample PIII treated at $400^{\circ} \mathrm{C}$ has the highest hardness of all the investigated samples. The hardness depth profiles for the implantations at $500^{\circ} \mathrm{C}$ are almost identical to those of the virgin samples.

\section{Discussions}

The comparison in Fig. 2 between the line shape parameter $S$ at $1 \mu \mathrm{m}$ and the hardness at the same depth shows that the overall evolution for the PIII treated samples coincides. This is however not the case for the virgin samples. While the remaining defect structure after the etching is clearly visible for the DBAR analysis, it has only limited influence on the hardness of the sample. The hardness of a material depends on both the presence of defects such as dislocations which hinder dislocation movement and the chemical bonds. The nitrogen content and $\mathrm{Fe}-\mathrm{N}$ phases of an identical set of samples was investigated by Jirásková et al. [6]. The polished and etched samples showed an increase in relative representation of $\mathrm{Fe}-\mathrm{N}$ phases with high nitrogen content $\left(\gamma-\mathrm{Fe}_{4} \mathrm{~N}, \varepsilon-\mathrm{Fe}_{3-x} \mathrm{~N}\right.$, and $\left.\varepsilon-\mathrm{Fe}_{2} \mathrm{~N}\right)$. It can thus be concluded that the presence of these nitrides results in the hardening of the material and the increase in the $S$ parameter. The formation of interfaces between the nitrides and the $\alpha$-Fe matrix with additional transformation dislocations increases the hardness and the $S$ parameter. The $S$ parameter can however also be increased by the decrease in the average electron density in the nitrides [7].

\section{Acknowledgments}

This research was supported by the IAP program P5/01 of the Belgian Science Policy Office.

\section{References}

[1] G.A. Collins, R. Hutchings, K.T. Short, J. Tendys, C.H. Van Der Valk, Surf. Coat. Technol. 84, 537 (1996).

[2] J. De Baerdemaeker, J. Colaux, G. Terwagne, C. Dauwe, Radiat. Phys. Chem. 68, 605 (2003).

[3] H.E. Schaefer, Phys. Status Solidi A 102, 47 (1987).

[4] J.F. Ziegler, J.P. Biersack, U. Liimark, The Stopping and Range of Ions in Matter, Pergamon Press, New York 1999.

[5] J. De Baerdemaeker, Ph.D. thesis, Ghent University, 2004.

[6] Y. Jirásková, C. Blawert, O. Schneeweiss, V. Peřina, A. Macková, Phys. Status Solidi A 189, 971 (2002).

[7] N.G. Chechenin, A. van Veen, R.E. Galindo, H. Schut, A. Chezan, D.O. Boerma, Mater. Sci. Forum 363-365, 493 (2001). 